Brane Senegačnik

Filozofska fakulteta

Ljubljana

\title{
LUKRECIJEV STRAH PRED SMRTJO IN PRED BOGOVI
}

Posebno vprašanje $\mathrm{v}$ Lukrecijevi poeziji predstavlja njegov odnos do smrti. Občutje strahu, ki ga vzbuja misel na smrt, občutje njene skrivnostne, vztrajne navzočnosti v srcu življenja je v njegovi veliki pesnitvi izraženo tako sugestivno, da je težko dvomiti o njegovi pristnosti. Lukrecij se kot epikurejec proti temu strahu seveda bori $z$ vso močjo razuma, še več: izvor tega strahu neločljivo povezuje s strahom pred bogovi in njihovim zemeljskim, zlasti pa pozemeljskim kaznovanjem človeka in to celo napravi za osnovno temo svoje pesniške izpovedi in filozofije. A neka zagonetna senca noče in noče izginiti in zdi se, kakor da iz ozadja še vedno tiho, a razločno odmeva misel: Media vita in morte sumus.

Poseben poudarek, ki ga je dal tej problematiki Lukrecij, so opazili mnogi interpreti (npr. Bailey (1), Boyance(2)), nekateri pa so celo sodili, da se skriva v tem dvojnem strahu ključ za razumevanje njegove duhovne podobe.

Očitno je, da je Lukrecij s tem, ko je pripisal strahu pred smrtjo in pred bogovi tako velik pomen in ko je po njegovem prepričanju postalo iztrebljenje le-tega ključna, če že ne izključna naloga nauka, na katerega je prisegal, potegnil najbolj svojsko potezo in se tudi najizraziteje oddaljil od duha Epikurove filozofije. Ta si je v nasprotju $\mathrm{z}$ rimskim pesnikom zadala bolj "pozitivne" naloge, predvsem pa je bilo $\mathrm{v}$ njej manj strastnih, kaj šele militantnih potez, ki so ji v bistvu tuje in celo nasprotne. Vzroke za to vidijo nekateri interpreti predvsem $v$ psihološkem ustroju Lukrecijeve osebnosti, ki je bil.po njihovem mnenju bistveno drugačen od Epikurovega. Epikur začenja svoje Maksime $\mathrm{z}$ izjavo o blaženosti bogov, ki ne poznajo nobenih težav in ki jih ne vznemirjata ne jeza ne zasluga; to izjavo ponovi tudi Lukrecij $v$ prvih dveh knjigah (prim. De Rer. Nat. I 44 .49; II 646 -651). Epikur se želi osvoboditi mitov o bogovih, toda njegova želja je blaga in umerjena, $v$ njej ni ničesar, kar bi ustrezalo Lukrecijevim silovitim antiteističnim izbruhom. (Podobno razhajanje, ki naj bi izviralo iz značajskih razlik, vidijo ti interpreti tudi pri političnih nazorih: Epikur je živel v obdobju, ko je politično življenje v Atenah propadlo in izgubilo svoj praktični učinek; zato opozarja svoje učence, da politični ugled in položaj ne pomenita nikakršnega jamstva za osebno varnost. Lukrecij je živel $v$ dobi silovitih nemirov in se - očitno - izogibal političnemu življenju, vendar pa ga je globoko prizadevalo spoznanje o vplivu, ki ga ima to na človeško srečo in značaj, ter si vroče želel rešiti svoje rojake pred njegovo tiranijo. Prelivanje krvi in politična ambicioznost sta se mu gnusila (prim. III 70 -78), skratka, kljub deklarirani želji doseči globoki mir, je iz pesnitve očitno, da ga ni dosegel; in morda mu to ni uspelo prav zaradi strastnega in ognjevitega temperamenta. Odkod tako silovito negativno stališče do vsega religioznega? Temu problemu se posebej obsežno posveča italijanski literarni kritik Luciano Perelli v svoji knjigi Lukrecij, pesnik tesnobe. (3). Najprej omenja precej razširjeno razlago, $\mathrm{ki}$ so jo anticipirali že francoski in angleški interpreti $\mathrm{v}$ devetnajstem stoletju, $v$ drugi polovici tega stoletja pa povzeli psihoanalitiki, namreč, 
da je bil Lukrecij potlačen mistik, ki je skušal premagati globoko vsajen strah pred smrtjo tako, da se je zatekel k epikurejski filozofiji, njegov antireligiozni posmeh pa je bil le preobleka njegovega najbolj notranjega občutja in naj bi le potrjeval, kako silna je bila tesnoba, ki jo je občutil spričo božanskega. $Z$ ozirom na razmeroma izrazite skeptične poteze dobe, $v$ kateri je živel, je njegovo neprestano in silovito zatrjevanje, da so religiozni strahovi temeljni vzrok človeške nesreče, očitno nesorazmerno s prevladujočim občutjem življenja in kaže na nenormalno razsežnost njegovih religioznih strahov. Perelli v tej razlagi sicer vidi zrno resnice, a se mu zdi vse preveč preprosta (celo simplicistična), ker ne upošteva posebnosti Lukrecijevega religioznega občutja niti mnogovrstnosti religioznega občutja v njegovem času. To vprašanje je nasploh tako kompleksno, da nanj ni mogoče odgovoriti dokončno. Lukrecijev strah pred smrtjo v resnici ni strah pred kaznimi, ki človeka doletijo v Aherontu - tesnobno občutje smrti v njem je povzdignjeno na višjo in bolj nedoločno raven. Prav tako ni mogoče reči, da so v Lukreciju še sledi praznoverja - kot npr. v Katulu - ki bi jih skušal izbrisati s svojo odločitvijo za Epikurov nauk; njegov religiozni strah je mnogo bolj vzvišen: rojeva se pod pritiskom teže vesolja, iz strahu pred neznano prihodnostjo, ki je odtegnjena našemu nadzoru, iz paničnega občutja narave. Zato bi po Perelliju smeli Lukrecijevo religioznost imenovati panično iracionalno občutje in je ne bi smeli razlagati kot rezultat duha časa: kar jo loči od njega, je prav paničnost in pa posebne značilnosti čustvovanja. Kakorkoli že je Lukrecijeva religioznost na psihološki ravni osebna, nezvedljivo individualna, pa je vseeno ne moremo iztrgati iz okvira religioznosti njegovega časa. Glede te obstajata dve glavni stališči. Po prvem je za Cezarjevo dobo najznačilnejša skepsa, vsaj med višjimi sloji; strah pred zagrobnim življenjem naj tako ne bi bil močno ražsirjen in Lukrecijeva polemika bi potemtakem izvirala bodisi iz grškega epikurejstva bodisi iz pretirano poudarjenih osebnih motivov. To stališče je včasih nekoliko korigirano $\mathrm{z}$ razlago, da je med ljudstvom strah pred onstranstvom vendarle bil precej razširjen pod etruščanskim vplivom; Lukrecij naj bi torej skušal s svojim delom pomagati, da bi se ljudstvo osvobodilo tega sredstva politične prisile. Drugo stališče pa poudarja mnoge vidike religioznosti v tem času, ki je zajemala tudi izobražene ljudi; po tej tezi Lukrecijeva polemika seveda ni bila anahronistična in je bila usmerjena proti realno obstoječemu nasprotniku. V obravnavanem obdobju res najdemo primere odkritega skepticizma, ob tem pa tudi pravo prerojenje religioznega duha - dvojnost, $\mathrm{ki}$ je sploh značilna za prelomna in kritična obdobja. K temu je treba dodati, da v zadnjem stoletju republike stara rimska religija zaradi anahronističnih predstav o življenju, na katerih je bila utemljena, in zaradi vztrajanja pri pedantnem izpolnjevanju preživelih norm ni bila več iskreno občutena in zdelo se je, da nima več učinka; vendar pa je bila še zmerom v uradni veljavi in je pomenila učinkovito sredstvo politične kontrole $v$ rokah predstavnikov starega plemstva. Strah pred bogovi $z$ upadom vere $v$ stare religiozne predstave torej ni povsem izginil, temveč se je prenesel $v$ druge oblike: stari občutek podrejenosti in negotovosti pred skrivnostno božjo voljo se je torej v veliki meri ohranil. Obnavljali so se etruščanski obredi, ki so vključevali vedeževanje o prihodnosti na podlagi opazovanja bliska in drugih nebesnih znamenj; podobe $\mathrm{z}$ nagrobnikov, nastalih $\mathrm{v}$ tistem času, pa kažejo, da so religiozne predstave močno spodbujale strah pred posmrtnim življenjem in demonskimi silami. Še bolj razširjene kot etruščansko vedeževanje pa so bile različne oblike astrologije in magijskih obredov, ki so prihajali 
z Vzhoda, in misterijske religije grško-orientalskega izvora: Dionizov kult, kult Kibele (Magna Mater), Izidin in Mitrov kult. Kot rečeno, se te religije niso širile le med preprostim prebivalstvom nižjih slojev, temveč so pristopali $\mathrm{k}$ njim tudi visoko izobraženi posamezniki visokega rodu. Kot značilen odsev te dobe navaja Perelli Katula: v njem lahko prepoznamo mnoge karakteristične elemente tedanje heterogene religioznosti: misterijska duhovnost, polbarbarski, orgiastični Demetrin kult, fatalizem in praznoverni strahovi, med vsem tem pa sledovi tradicionalnih rimskih obredov, predvsem družinski kult umrlih prednikov. Vse te ugotovitve tako nagibljejo tehtnico $\mathrm{v}$ prid drugemu stališču, da je bilo religiozno občutenje $\mathrm{v}$ Lukrecijevem času zelo živo in da se pesnik v svojem antireligioznem zanosu ni bojeval s prikaznimi iz preteklosti, ki bi živele samo še med preprostimi ljudmi. Po drugi strani pa je spet res, da so takšno nesmiselnost njegovemu boju očitali že njegovi najstarejši nasprotniki: Cicero je npr. govoril o tem, da je boj epikurejcev prazen, saj v mitološke prikazni ne verujejo več niti starke. Ta očitek pa je problematičen, kajti četudi ni bilo več vere $v$ mitološka bitja, so praktično vse religije ohranile vero v nesmrtnost, večnost duše - in prav to je dejansko osnovni predmet epikurejske kritike.

$\mathrm{Da}$ bi postala jasnejša zveza med Lukrecijevim antireligioznim bojem in njegovim zgodovinskim kontekstom, je treba imeti pred očmi, da je bil Lukrecijev odnos do stare rimske religije drugačen kot do mističnih, filozofskih in okultističnih oblik religije. Najsilovitejše napade usmerja zoper tradicionalno državno religijo, religijo neaktualne (ali kot pravi Perelli, celo protiaktualne) vsebine $z$ obsežnim obrednim aparatom, ceremonijami in svetišči. V to polemiko sodi epizoda $z$ Ifigenijo (prim. De Rer. Nat. I 84 -100), žrtvovanje telička (II 352 - 366), napad na svobodne mislece, ki pa ob težavah zopet zapadejo opravljanju obredov (III 41 -54), opis napačne pobožnosti (V 1198 - 1202), kritika augurskega vedeževanja iz bliskov (VI 379 - 422) in podoba v svetišča nametanih trupel tistih, ki so umrli za kugo (VI 1272 1275). Po drugi strani pa je zanimivo, da kljub vehementni kritiki na formalizem zvedene uradne religije nekatere teme svojega najglobljega poetičnega občutja najde prav $\mathrm{v}$ izvornih rimskih obredih. Zdi se, kot da bi $\mathrm{v}$ naravi, stvareh in dogodkih zaznaval navzočnost in voljo temnih, pretečih sil: te sile veliko bolj spominjajo na brezosebna numina stare rimske religije, zbujajoča občutja groze (horror), kakor na antropomorfne grške bogove. Spričo te podtalne in morda nezavedne vezi z izvorno religioznostjo postanejo razumljivi svetlejši toni Lukrecijevih stihov, kadar govori o manj formalističnih vidikih religioznega življenja, kadar se posveča njeni mistični razsežnosti, negotovemu občutju strahu, $\mathrm{ki}$ se poraja pred onstranskim in nadnaravnim: namesto prezira in posmeha tedaj avtorja napolnjuje nekakšna mistična tesnoba. Njegovemu pronicljivemu duhu ne uide, da prihaja od misterijskih oblik religije in njihovih filozofskih predelav večja nevarnost za človekovo dušo kot od uradne rimske religije: to $\mathrm{mu}$ potrjuje široka razprostranjenost teh doktrin med rimsko kulturno elito, a tudi lastna izkušnja njihove privlačnosti. Odlomek iz prve knjige, v katerem si prizadeva, sklicujoč se na načela epikurejske šole, razpršiti strah pred smrtjo, ki izvira iz religioznih naukov (De Rer. Nat.I 102 135), lahko zelo ustrezno umestimo $v$ duhovni ambient tedanjega časa $v$ Rimu. Te vrstice se nanašajo predvsem na pitagorejska verovanja. Pri naštevanju različnih hipotez o usodi, ki doleti dušo po smrti, namenja pesnik najpomembnejše mesto pitagorejski razlagi. Perelli meni, da je Lukrecij očitno hotel osvetliti kontradikcije med pitagorejstvom pesnika Enija in med 
novejšimi predstavniki te doktrine. Enij je sprejemal metempsihozo, vendar ob njej tudi razlago egipčanskega izvora, po kateri je podoba umrlega odšla $\mathrm{v}$ podzemlje, njegova duša pa se je povzpela v nebo. Stari pitagorejci so verjeli v posmrtno kazen v Hadu, v Lukrecijevem času pa je med njimi prevladovalo prepričanje, da "pekel" obstaja na površju zemlje. Vendar pa je $v$ tem času mogoče najti tudi znotraj tega duhovno-religioznega kroga sledove drugačnih predstav o kazni grešnikov: Perelli omenja Somnium Scipionis (De Rep. VI 26). kjer Cicero pod vplivom pitagorejskih predstav govori o tem, kako duše grešnikov poletavajo semtertja po zraku, ki obkroža našo zemljo.

Lukrecij se torej okorišča s polemičnimi stališči v okviru iste doktrine in ima za vir dvomov in nemira obstoj mnogih različic nauka o usodi duše, ki so jih širili pitagorejci. Važno pa je opozoriti na to, da sploh ne omenja "pozitivne" strani pitagorejskega verovanja o duši, po katerem se duše dobrih vzpnejo v nebo (nebesa) ter - kot vselej - vztraja samo pri tistih vidikih nasprotnih naukov, ki povzročajo v ljudeh tesnobo, in molči o onih, ki $v$ njih vzbujajo upanje na srečno prihodnost. Na koncu odlomka govori o prikaznih $\mathrm{v}$ snu ali celo $\mathrm{v}$ budnem stanju, ki povzročajo religiozni strah. Znano je, da je delovanje tajnega krožka Nigidija Figula (živel je v Rimu v Cezarjevem času), temeljilo na nekaterih pitagorejskih prvinah. Med višjimi sloji so se religiozno in mistično navdahnjeni duhovi najraje usmerjali v pitagorejstvo, ki je imelo že stoletja globoke korenine $v$ rimski družbi in je dobro zadovoljevalo potrebe intelektualcev. Pitagorejstvo je igralo pomembno vlogo $v$ rimski kulturi $v$ prvem stoletju pred Kristusom, zlasti po zaslugi Nigidija Figula, ki je prenovil religiozno življenje in ga prilagodil času: preoblikoval je pitagorejstvo $\mathrm{v}$ misterijsko sekto in pomešal filozofijo $\mathrm{z}$ okultizmom, magijo in astrologijo ter združil temačne oblike religioznosti z intelektualističnimi težnjami. Njegov krožek se je ukvarjal s spiritizmom in nekromantijo. Pitagorejci so verjeli, da se duše mrtvih prikazujejo $v$ snu ali pa da jih je mogoče priklicati z magičnimi postopki, vendar pa podoba, ki se je prikazala, ni bila prava duša, temvel le bled privid. To pa pravzaprav ustreza smislu Lukrecijevih besed, po katerih lahko vpadejo v človekovo oko simulacra umrlih, ki so še za življenja v svojem strujanju odtekla s teles in še po smrti nekaj časa plavajo $\mathrm{v}$ zraku (prim. de Rer. Nat. IV 33 sqq). Predvsem je pomembno, da v celotnem odlomku ni niti sledi o preziru pitagorejske doktrine, pa tudi ne silovite polemičnosti; nasprotno, poudarek je na dvomih in strahovih, ki jih vzbujajo sugestivne teorije nasprotnikov.

$\mathrm{Ob}$ tem velja opozoriti, da se Lukrecij strinja s pitagorejsko simbolično interpretacijo tradicionalnih mitov o posmrtni kazni, četudi je njegovo izhodišče drugačno. Zanimivo je tudi, kako razširjen je bil $v$ tem času kult boginje Kibele (Magna Mater), ki je zaradi svojih moralnih, duhovnih in eshatoloških vsebin pritegnil tudi številne druge izobražene duhove razen pitagorejskih krogov (Katula, Cecilija, Varona), čeprav je bil y osnovi primitiven in polbarbarski. Perelli je mnenja, da je Lukrecij po vsej verjetnosti uporabil alegorično Nigidijevo razlago tega kulta (torej pitagorejsko navdahnjeno) v ekskurzu, kjer opisuje Kibelin sprevod (prim. II 600 $660)$; še posebej se mu zdi to verjetno, ker se Lukrecijeva verzija razlikuje od Varonove.

Končno obstaja še ena točka, v kateri stoji Lukrecij blizu misterijskim in pitagorejskim religioznim nazorom: to je pričakovanje bližnjega konca sveta (prim. 
De Rer. Nat.II 1105 - 1170). Vzroki za takšno pričakovanje so najbrž raznovrstni, zagotovo pa so med njimi zgodovinski. Kriza rimske republike je bila zelo ugodna podlaga za širjenje kataklizmičnega občutja in za, če smemo tako reči, njegovo aktualizacijo: veliko je bilo razlag, po katerih se je tedaj približal čas končne katastrofe, ki so ga napovedovali različni religiozni in filozofski nauki, osnovani na cikličnem pojmovanju časa .

Tudi ta zadnji vidik govori za to, da Lukrecijeve polemične protireligiozne osti niso bile naperjene $\mathrm{v}$ prazno, da niso bile nekakšen donkihotski boj proti strahovom iz preteklosti. Zanimivo pa je, da v njegovih vizijah o koncu sveta ni nobenega namiga na palingenezo, na prerojenje sveta in človeštva, na nastop novega velikega leta, kar so oznanjali stoiki in večina vzhodnjaških astrologov. Pri Lukreciju je čutiti le srhljivo pričakovanje končne katastrofe, kar zopet namiguje na možnost vpliva neopitagorejskega kroga Nigidija Figula, kjer so bile žive ideje t. i. mazdaistov o skorajšnjem nepreklicnem in dokončnem uničenju sveta. Lukrecij je potemtakem živel sredi duhovnih tokov svojega časa, vendar na poseben način: tako da je, kot je to zelo pogosto pri pesnikih, videl zgolj eno stran zgodovinskih danosti in skozi svojo perspektivo spreminjal njihova razmerja. Kot že rečeno, je priznaval zgolj negativno plat religije: "metafizično" tesnobo, ki jo ta poraja, za njene odrešenjske vidike pa ostaja $v$ celoti zaprt in neobčutljiv. Kolikor vidi $v$ religiji glavni izvor človeškega nemira, zvesto sledi Epikuru, vendar je v njegovem času bilo stanje prej obratno kot $\mathrm{v}$ Epikurovem: $v$ prvem stoletju pred Kristusom sta negotovost in nemir zunanjega in notranjega življenja ljudi usmerjala $v$ religijo, da bi si tam poiskali varno zatočišče. Res pa je tudi, da večina religij te dobe $v$ resnici ni prinašala notranjega miru in od tod morda tudi Lukrecijeva odločitev, da bo s pesniškimi sredstvi nastopal proti njej. Ker ga nobeden od kultov in nobena od mističnih filozofij nista mogli osvoboditi tesnobe, se je obrnil k epikurejstvu, kjer je našel rešitev dveh svojih glavnih problemov: epikurejstvo je iztrebljalo korenine religioznega strahu in razreševalo skrivnost kozmosa. Ta obrat ima Perelli zgolj za drugačno obliko religiozne odločitve. Epikur dejansko nastopa v pesnitvi kot bog, ki je odrešil človeštvo pred demonskimi silami religije in razvozlal uganko o ustroju vesolja. Ni mogoče prezreti, da pesnika tedaj, ko slavi vserazsvetljujočo moč epikurejske doktrine, ki razmika "obzidja sveta" in odstira pogled v neskončno praznino, spreletavajo občutki, na las podobni religioznim: v njih se $v$ srhu mešata slast in groza, ki zaznamujeta človekovo doživljanje neskončnega (De Rer. Nat. II $28-30$ ):

His ibi me rebus quaedam divina voluptas percipit atque horror, quod sic natura tua vi tam manifesta patens ex omni parte retecta est.

V tem je očitno nekakšno notranje protislovje: medtem ko Lukrecij izpoveduje in slavi nauk, ki uči, da je sreča v odsotnosti slehemega vznemirjenja, še zlasti pa religioznega, sam v svojem navdušenju občuti prav to.

Tesnobno občutje smrti oziroma nikdar dokončno premagana tesnoba zaradi nje je, kot rečeno, ena najbolj skrivnostnih in obnem ostro izrisanih pesnikovih značilnosti. Ne srečamo pa je le $v$ povezavi $s$ strahom pred bogovi, marveč tudi $v$ 
plastičnih opisih človeške smrti, kot je npr. "znanstveno" natančen opis smrtne agonije (De rer. Nat. III $525-530$ ):
Denique saepe hominem paulatim cernimus ire et membratim vitalem deperdere sensum; in pedibus primum digitos livescere et unguis, inde pedes et crura mori, post inde per artus ire alios tractim gelidi vestigia leti.

Podobno občutje veje tudi iz prizorov groze pred neskončnimi razsežnostmi kozmosa. le težko bi pritrdili Boyancejevi trditvi, da je občutje neskončnega pri Lukreciju strogo nasprotno Pascalovemu; da bi lahko Lukrecij rekel, da ga tišina neskončnih prostorov pomirja, ker ga prepričuje $v$ odsotnost muhastih in zlovoljnih božanstev. Gotovo je takšno občutje pristno epikurejsko in gotovo je, da ga Lukrecij izpoveduje $s$ hlastnim mavdušenjem, pa vendar trepetavi in vzneseni ton njegovih besed $\mathrm{v}$ bralcu ne pusti vtisa o pesnikovi pomirjenosti. Četudi so pred nami le primeri, na katerih naj bi se potrdila odrešujoča moč Epikurovega nauka, in celo če beremo sam slavospev Velikemu Mojstru (verzi De Rer. Nat. II 28 - 30), smo priče pesnikovemu neizprosnemu in iskrenemu boju s strašno tišino neskončnih prostorov. Naj bo luč "znanosti" kot bi lahko rekli v tem kontekstu epikurejski ontologiji) še tako zmagoslavna - una traccia del' ansia permane, kot v že večkrat navedenem delu večkrat pripomne Perelli.

Težko je reči, ali je ta vztrajna tesnoba posledica pesnikove psihične konstitucije; to vprašanje seveda nujno ostaja brez dokončnega odgovora, a nenazadnje za interpretacijo umetnine niti ni bistveno. Vsekakor pa je moč pokazati na šibke točke epikurejske tolažbe $v$ filozofskem oziru, če povemo ustrezneje, na njeno nemoč, premagati eksistencialno tesnobo. Osnovno izhodišče epikurejske etike pri premagovanju smrti pa tudi življenjskih tegob (telesnih in duševnih bolečin) je, da nobena stvar in $s$ tem tudi nobeno zlo ni neskončno. $O$ tem govorijo zelo jasno nekatere od Epikurovih Maksim (Kyriai Doxai), npr. četrta ali zlasti dvajseta, v kateri izrecno pravi, da pomaga človeku do popolnega življenja razum, ki je dodobra preudaril, kaj je konec in cilj vsega mesa, in se je znebil strahu pred večnostjo. To misel najdemo izrecno izraženo tudi pri Lukreciju, a - kar je značilno - ne $v$ zvezi z ugodjem (naslado), temveč s človeškimi bolečinami in posmrtno kaznijo (De Rer. Nat. I $107-111$ ):

Et merito. Nam si certam finem esse viderent aerumnarum homines, aliqua ratione valerent religionibus atque minis obsistere vatum.

Nunc ratio nulla est restandi, nulla facultas, aeternas quoniam poenas in morte timendum.

Srčika človekovega etičnega napora, $s$ katerim si pridobi srečo, je v tem, da zna postaviti kvantitativno in časovno mejo vsakemu ugodju in bolečini. To je sicer 
stara grška misel (metron ariston), vendar je $\mathrm{v}$ epikurejski izpeljavi zaostrena ter zadeva - in to bistveno - tudi človekovo religiozno zavest. Človekov strah pred večno posmrtno kaznijo je izničen s poudarjanjem omejenosti in končnosti vsake stvari, kot lepo ilustrirajo tile Lukrecijevi verzi (De Rer. Nat. I 75 - 77):

unde refert nobis victor quid possit oriri,

quid nequeat, finita potestas denique cuique

quanam sit ratione alte terminus haerens.

$\mathrm{Na}$ ta način je odpravljeno nekaj, čemur bi pogojno lahko rekli pozitivni vidik neskončnosti ( $\mathrm{v}$ našem primeru gre dejansko za kontinuiranje enega samega "temnega" življenjskega pojava, saj so posmrtne kazni pravzaprav samo $\mathrm{v}$ večnost podaljšane in fantazijsko predelane oblike zemeljskega trpljenja). To je značilna poteza epikurejske logike, po kateri je najvišje ugodje odsotnost neugodja (he katastematike hedone). Toda s tem ni mogoče odpraviti drugega vidika neskončnosti, spet pogojno rečeno, njene negativne strani. Lahko je namreč priklicati predstavo o minljivosti vseh stvari in jo projicirati tudi na mitološki in religiozni svet, vendar človekova zavest tedaj neizogibno udari ob nič. Človek se sreča z nečim neimenljivim in nezapopadljivim, kar zadeva njegovo bitje v celoti in česar resničnosti zaradi svoje neposredne izkušnje ne more zanikati. Dejansko šele ta izkušnja omogoči predstavo ali bolje rečeno zavest o nemožnosti predstave neskončnega (in celo o nemožnosti misliti neskončno), tudi če je to "pozitivno" koncipirano in ima ime, kot npr. Bog. (Morda zveni to izvajanje nekako retorično in šolsko dialektično. Temu se izognemo, če igre biti in niča, slovesno preoblečene teze in antiteze, ne hipostaziramo in $\mathrm{s}$ tem ne zvedemo človeške osebe le na figuro $v$ tej igri. Pravo vsebino pa te besede dobijo seveda samo tedaj, ko jih postavimo na temelj dramatične človeške - svoje lastne izkušnje). Epikurejstvo skuša doseči svoj cilj tako, da iz človekove zavesti "izžene" misel in občutje neskončnega oz. večnega. Zato mora po eni strani nujno doseči, da se človek ne bi več oprijemal antropomorfne podobe vesolja in bi tako opustil tudi identifikacijo s svojim intuitivno dojetim jazom - osebo ter bi se dojemal kot minljiva in naključna konfiguracija atomov. Po drugi strani pa bi se skladno s tem moral odreči tudi nekaterim bistvenim elementom človeškega bitja (čustvom), da bi dosegel vrhunec ugodja, ugodje v miru. (Dejansko pa je epikurejstvo doživelo socialni razmah $\mathrm{v}$ manj radikalnih oblikah in predvsem kot nauk za vsakdanje življenje, kjer se filozofske postavke ne izpolnjujejo strogo dosledno.) $V$ tem je po našem mnenju glavna težava te filozofije, $\mathrm{ki}$ je za svojo etično orientacijo uporabljala sredstva znanosti. Problematičnost, če že ne nujno neuspešnost, take naravnanosti je posebej dobro izkusil novi vek, zlasti naše stoletje (marksizem, absolutna relativizacija resnice). Perelli ugotavlja, da Lukrecija epikurejska razlaga sveta ni odrešila religiozne tesnobe, čeprav je brez zadržka in strastno pristajal nanjo. Dodali bi lahko, da je njegov nemir izviral iz tesnobnega doživljanja neskončnosti prostorov in večnosti, ki se je porajalo največ prav ob pretresanju religioznih predstav in celo ob zanosni razlagi samega Epikurovega nauka. Pesnika je namreč oblival horror vacui celo medtem, ko je občudujoč preudarjal domet in posledice ontološke teorije svojega učitelja. Po naši sodbi ni prazno reči, da se je to zgodilo zato, ker ni mogel z vsem 
svojim bitjem slediti analitičnim prijemom, s katerimi je grški mojster razgaljal vesolje, temveč je v njem odmeval tudi nerazložljivi "večni molk tega brezkončnega prostorja" (Pascal).

\section{LITERATURA}

1. Titi Lucreti Cari De Rerum Natura, Edited with prolegomena, Critical Apparatus, Translation and Commentary by Cyril Bailey, Oxford 1947.

2. P. Boyance, Lucrece et l' epicurisme, Paris 1963.

3. L. Perelli, Lucrezio poeta dell' angoscia, Firenze 1969.

\section{SUMMARY}

Lucretius was as zealous fighter against religion as any other poet or thinker in history (e. g. much more zealous as Epicurus himself). Believing the fear of death caused by religious myths to be the main obstacle to human happiness (defined as the living in the perfect impassivity), he considered extirpation of religion the principal goal of epicurean philosophy. He was severe in rejecting oficially practicised old Roman rites; however, he considered secret rites -- such as those of the Pythagoreans, which seeemed to him to be more persuasive and suggestive - to be even more dangerous, though there was a slight resemblance between Pythagorean and Lucretius' teaching regarding the symbolic interpretation of traditional myths about punishment in the after-life and about expectation of the imminent end of the world. Of course, we must not overlook that this great poet always took into account the »dark side« of religious doctrines. Several scholars assert that Lucretius to all apperances never set his mind fully free of what we call metaphysical anxiety. The author of the present article makes an effort to represent this very »metaphysical sensibility « as the source of the deepest feelings and poetical expressions in the De Rerum Natura. 